\title{
Kabuverdianu moderno: alguns aspectos fonológicos
}

Shirley Freitas

Universidade da Integração Internacional da Lusofonia Afro-Brasileira (UNILAB), Brasil

\section{Introdução}

O kabuverdianu moderno é uma língua crioula de base portuguesa falada nas ilhas de Cabo Verde. Neste capítulo, serão discutidos aspectos fonológicos dessa língua, concentrando-se na variedade falada em Santiago, a partir da qual as demais se desenvolveram. Inicialmente, a seção 1 apresenta alguns traços gerais do kabuverdianu, como o estatuto da língua dentro do arquipélago. Em seguida, são mostrados os inventários fonológicos de vogais e consoantes (seções 2 e 3, respectivamente), incluindo o quadro de ditongos e a discussão acerca do estatuto das consoantes nasalizadas. Na seção 4 e subseções, trata-se da estrutura silábica e dos segmentos passíveis de preencher as posições de onset, núcleo e coda. Por fim, a seção 5 apresenta uma síntese do capítulo.

\section{Kabuverdianu moderno}

O kabuverdianu moderno é falado nas nove ilhas habitadas do arquipélago de Cabo Verde: Santiago, Fogo, Maio, Brava, Santo Antão, São Vicente, São Nicolau, Boa Vista e Sal. Além disso, segundo Silva (2008, p.25), muitos cabo-verdianos emigraram para outros países e, com eles, a sua língua também foi levada para além de Cabo Verde. Assim, atualmente muitos falantes de kabuverdianu moram em Portugal, França e Estados Unidos. Falado em diversos lugares, o kabuverdianu, como qualquer outra língua, apresenta variações, o que, contudo, não significa línguas diferentes. Essas variações são decorrentes das próprias características da colonização das diversas ilhas (diferentes períodos e agentes colonizadores) e também da distância entre as mesmas (Rodrigues, 2007, p. 13; Lopes, 2012, p. 9).

A despeito das diferenças, as variedades dialetais do kabuverdianu podem ser reunidas em dois grandes grupos (Quint, 2000a, p. 9): (i) um nas ilhas de Barlavento, cuja variedade é de desenvolvimento mais recente. As influências 
africanas são menores dentro do léxico e a gramática é próxima do português, sobretudo nos âmbitos fonético e fonológico; (ii) e outro nas ilhas de Sotavento, que possuem uma variedade mais antiga, permeada de palavras africanas e com aspectos fonéticos diferentes do português. Quint (2000b, p. 80) afirma que os dialetos do sul estariam mais próximos do crioulo falado nos primeiros tempos, formado a partir das línguas africanas e do português dos séculos XVI e XVII. Essas variedades conservariam tanto os traços africanos do antigo crioulo (nos âmbitos do vocabulário e do sistema verbal) quanto a pronúncia do português dos séculos XVI e XVII, que se diferenciava sobretudo com relação às vogais átonas. É possível ainda distinguir a variedade falada em Santo Antão, que, para Quint (2000a, p. 9-10), é tão diferente no âmbito das evoluções fonéticas e morfológicas que poderia estar em um grupo à parte. Schuchardt (1887, p. 137) também aponta a particularidade da fala de Santo Antão. Segundo o autor, o dialeto dessa ilha conservou muitos traços do português (o que, nas demais ilhas, seria menor) em virtude de seu isolamento anterior com relação ao resto do arquipélago, de sua colonização mais tardia e do grande número de europeus (brancos).

Dentre as diversas variedades de kabuverdianu, este estudo se concentra na falada na região de Sotavento, especialmente em Santiago, já que foi a partir da variedade dessa área que se formaram as demais. Tendo sido as primeiras a serem habitadas, as ilhas de Sotavento congregam as variedades mais antigas e conservadoras da língua e as que vêm despertando a maior parte da atenção dos estudiosos (Rodrigues, 2007, p. 144-197). Mais precisamente em Santiago, onde se iniciou o povoamento do arquipélago, segundo Brüser et al. (2002, p. 19), é falado "[...] um dos mais antigos crioulos de base europeia ainda vivos, ou talvez até o mais antigo.” A ilha de Santiago é considerada por Quint (2000a, p. 5) como a mais africana do arquipélago nos âmbitos étnico e cultural pelo fato de o povoamento ter se efetuado sobremaneira por escravos vindos do continente. Já o crioulo santiaguense, nas palavras de Quint (2000b, p. 96), dentre as demais variedades, é o mais antigo, o mais conservador e o mais distante do português. Lopes (2012, p. 4-6) defende ainda a hipótese de que o crioulo falado nessa ilha, por sua antiguidade e conservadorismo, seria o mais próximo do protocrioulo a partir do qual derivaram as demais variedades do kabuverdianu e mesmo outras línguas crioulas, como o papiamentu e o kriyol de Guiné Bissau e Casamança.

Quanto ao seu estatuto, o kabuverdianu é a língua materna de grande parte da população cabo-verdiana, sendo o sistema linguístico preferido para a comunicação diária informal, sobretudo no registro falado. Por outro lado, a língua oficial do país é o português - Cabo Verde inclusive faz parte do grupo dos Países Africanos de Língua Oficial Portuguesa (PALOP) -, usado na escolarização, na 
mídia, nos documentos oficiais e na esfera político-econômica (Quint, 2000b; Pratas, 2002; Silva, 2008; Lopes, 2012; Miranda, 2013). Esse quadro cria uma situação de diglossia (Ferguson, 1959), no qual duas línguas convivem em um mesmo espaço, mas não gozam do mesmo status sociopolítico. Na sociedade cabo-verdiana, o uso do português é tão restrito aos registros mais formais que muitos habitantes de Santiago não falam nem compreendem de fato o português, a despeito de essa ser a língua oficial e estar presente na escolarização (Quint, 2000b; Miranda, 2013). Essa presença da língua portuguesa nas ilhas, mesmo depois do fim do domínio de Portugal na região, tem levado, de acordo com Rodrigues (2007, p. 243-247), à "descrioulização" do kabuverdianu. Em linhas gerais, nesse processo, o crioulo vai mudando em direção à sua língua de superstrato (no caso, o português), perdendo as características mais divergentes daquelas do lexificador. De fato, é possível observar, em Santiago, a presença de duas variedades mais gerais de crioulo: de um lado, o "crioulo fundo", com traços arcaicos e, de outro, o "crioulo leve", falado principalmente na capital e recebendo mais influências do português.

\section{Sistema vocálico}

No âmbito vocálico, o kabuverdianu possui os fonemas do quadro 1 (Brüser et al., 2002, p. 23; Lang et al., 2002, p. 61)':

Quadro 1: Fonemas vocálicos do kabuverdianu moderno

\begin{tabular}{|c|c|c|c|}
\hline--- & ANTERIORES & CENTRAIS & POSTERIORES \\
\hline Altas & $\mathrm{i}$ & & $\mathrm{u}$ \\
\hline Médias-altas & $\mathrm{e}$ & & $\mathrm{o}$ \\
\hline Médias-baixas & $\varepsilon$ & $\mathrm{e}$ & $\mathrm{o}$ \\
\hline Baixas & $\mathrm{a}$ & & \\
\hline
\end{tabular}

Além desse inventário, alguns autores admitem ainda que existem vogais nasais. Brüser et al. (2002, p. 23) defendem a existência de cinco vogais nasais, apontando para o fato de que, nesses contextos, a oposição entre as vogais

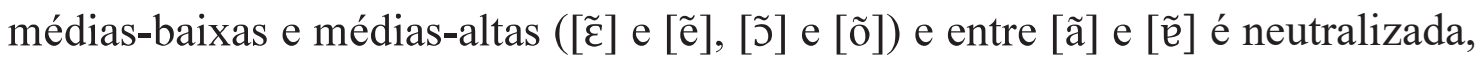
sendo o contexto o responsável por determinar a forma a ser usada. Lang et al. (2002, p. 61) também advogam a ocorrência de vogais nasais fonológicas: para eles, o sistema teria oito vogais nasais, correspondendo às realizações nasalizadas da série oral, diferindo destas somente pelo traço de nasalidade. Assim, ao quadro

1. Para Rodrigues (2007, p. 149), o kabuverdianu dispõe também de oito vogais, contudo, em lugar de /e/, estaria o /ə/. Assim, quando nos referirmos à presença do schwa no trabalho da autora, ele pode ser visto como equivalente a $/ \mathbf{e} /$. 
de Brüser et al. (2002, p. 23), os autores acrescentam os seguintes fonemas: / $\tilde{\varepsilon}$, ã, כ/. Rodrigues (2007, p. 153), por seu turno, apresenta uma postura diversa.

Para ela, do ponto de vista fonológico, não existem vogais nasais em kabuverdianu, mas vogais nasalizadas (vogal oral + consoante nasal): [i] (/iN/), [ẽ]

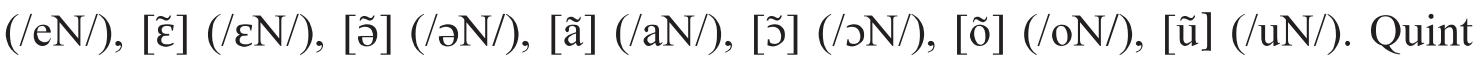
(2000a: 25) também defende a existência de vogais nasalizadas em kabuverdianu no âmbito fonológico (/VN/), mas, diferentemente de Rodrigues (2007, p. 153), considera que, nesses casos, não ocorre oposição entre [e] e [E], [o] e [ग], [a] e [e]. Desse modo, não há consenso sobre a atribuição de estatuto fonológico à série das vogais com o traço [+ nasal]. Lang et al. (2002), inclusive, muitas vezes, chamam as vogais nasais de nasalizadas (termo em geral empregado para se referir a elementos que sofreram um processo de nasalização no âmbito fonético), o que ilustra a dificuldade de definir se tais vogais constituem fonemas da língua ou não. Uma vez que, no kabuverdianu, não existe oposição entre vogais nasais e vogais nasalizadas (entre $/ \mathbf{i} /$ e /iN/, por exemplo), neste estudo, considera-se que não existem vogais nasais fonológicas na língua, mas vogais foneticamente nasalizadas, que correspondem, no âmbito fonológico, a uma vogal oral seguida de consoante nasal.

Além disso, defende-se que quando se tem uma vogal nasalizada, a oposição entre as vogais centrais ([a] e [e]) e as médias-altas e médias-baixas ([e] e [ع], [o] e [ग]) é neutralizada. Alguns comentários devem ser feitos sobre as vogais que possuem o traço [+ nasal]. De acordo com Brüser et al. (2002, p. 23) e Lang et al. (2002, p. 53-61), em posição final de palavra, geralmente essas vogais são seguidas pela nasal velar ([y]). Esses autores apontam ainda que a oposição entre vogais orais e nasais restringe-se à posição final de palavras, como se vê nos seguintes pares mínimos (exemplos retirados desses autores): $\mathrm{ri}^{2}\left[{ }^{\mathrm{I}} \mathrm{ri}\right]^{3}$ 'rir, sorrir' e rin ['rî(y)] 'rim', le ['le] 'ler' e len ['lẽ (y)] 'lado', manha

2. Os dados do kabuverdianu moderno aparecem em itálico e na sua grafia atual. No caso de nomes científicos, eles serão grafados entre aspas duplas. A grafia da língua segue o ALUPEC (CABO VERDE, 1998), proposta de um alfabeto unificado (de inspiração fonético-fonológica) para as ilhas de Cabo Verde como um primeiro passo para a padronização da língua. O alfabeto adotado possui 23 grafemas: $<a, b, d, e, f, g, h, i, j, k, l$, $m, n, \tilde{n}, o, p, r, s, t, u, v, x, z>$. A realização fonética de alguns símbolos gráficos (em virtude de não ser totalmente transparente) deve ser mencionada: (i) $<g>$ representa sempre [g], independentemente do segmento seguinte; (ii) $<h>$ de forma geral não é pronunciado; (iii) $<j>$ representa [3]; (iv) $<x>$ representa [ $]$; (v) $<d j>$ representa [dz]; (vi) $<t x>$ representa [tf]; (vii) $<l h>$ representa [K]; (viii) $<n h>$ representa [n].

3. As transcrições do kabuverdianu moderno tomam como base aquelas que aparecem no dicionário de Brüser et al. (2002), realizando modificações sustentadas pela descrição fonética de Rodrigues (2007). Essa postura foi tomada em virtude de as transcrições apresentarem algumas incoerências, com os autores, muitas vezes, parecendo confundir representação fonética com fonológica, como é o caso da representação das vogais nasais e do $<\mathrm{l}>$ velarizado. Assim, a fim de desfazer equívocos, foram adotadas algumas mudanças, dentre as quais se destacam: 
['ma.ñe] 'manha' e manhan ['ma.jẽe(y)] 'amanhã', po ['po] 'pôr, colocar' e pon ['põ(y)] 'pão', kru ['kru] 'cru' e krun ['ksũ(N)] '1. interjeição onomatopaica que imita o ruído de um embate etc, por exemplo, quando se fecha uma porta com estrondo, 2. emprega-se também para sugerir um procedimento rápido'. Além disso, Lang et al. (2002, p. 77) apontam ainda que, diante das consoantes nasais $/ \mathrm{m} /, / \mathrm{n} /$ e $/ \mathrm{n} /$ (ocorrendo em sílabas diferentes), não ocorrem vogais com o traço [+nasal], ou seja, não há espalhamento da nasalidade, como em kama ['ka.me] 'cama' (*['kẽ.me]), panéla [pe.'nc.le] (*[pẽ.'nc.le]) 'panela' e dinheru [di.'ne.ru] (*[di.!ne.ru]) 'dinheiro'.

Quanto às vogais médias-baixas, Rodrigues (2007, p. 149) discute seu estatuto fonológico. Ela aponta que Macedo (1979, p. 90-93 apud Rodrigues, 2007, p. 149) exclui /E/ e / $/$ do quadro fonológico, considerando-os alofones contextuais das médias-altas; já Veiga (1986, 1994, p. $92-93$ apud Rodrigues, 2007, p. 149) apresenta um posicionamento diferente, defendendo que as vogais médias-baixas constituem de fato fonemas da língua e apresentando pares mínimos para corro-

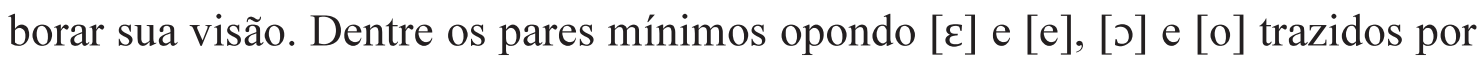
esse autor, citam-se: séra ['sc.re] '1. serra (ferramenta), 2. serra (montanha), 3. cera' e sera ['se.re] 'serrar'; féra ['fe.re] 'animal selvagem, fera' e fera ['fe.re] '1. festa popular, 2. mercado, feira'; óra ['J.re] 'hora' e ora ['o.re] 'orar, rezar'; róda ['ro.de] '1. roda, 2. (grande) quantidade, 3. arredores' e roda ['ro.de] '1. rodar, girar, 2. rodear, circundar' (exemplo retirado de Brüser et al., 2002, p. 679). Desse modo, fica ilustrada, então, a pertinência de considerar a série das vogais médias-baixas como fonemas da língua.

Ademais, segundo Rodrigues (2007, p. 152), as vogais médias-baixas geralmente ocorrem na sílaba tônica de palavras paroxítonas que terminam em vogal central, como se vê em kabésa [ke.'be.se] 'cabeça', manéra [me.'nc.re] 'maneira, modo', góta ['go.te] 'gota', bóka ['bo.ke] 'boca' (exemplos retirados da autora). A autora menciona ainda que, nas variedades da Sotavento, há alguns poucos casos

\footnotetext{
a. Emprego das africadas alveopalatais [t $\mathrm{f}]$ e [dz] em lugar das oclusivas palatais [c] e [f];

b. Emprego da vibrante simples $[r]$ em lugar da vibrante múltipla $[r]$;

c. Emprego da lateral velarizada em posição de coda (medial e final) [ł] em lugar de [1] (realização confirmada a partir de gravações com falante nativo do kabuverdianu);

d. Representação das vogais nasalizadas com o til, em vez de colocar uma vogal oral seguida de consoante nasal. Se tal representação fosse adotada, significaria dizer que a consoante nasal é pronunciada, o que não se acredita ser o caso mais geral;

e. Nas consoantes (pré-)nasalizadas, o elemento nasal aparece sobrescrito, e não no mesmo nível da consoante;

f. Nas palavras reduplicadas, será marcado somente o acento primário. Nesses casos, Brüser et al. (2002, p. 49) consideram duas sílabas tônicas, o que se contrapõe às próprias características de formas reduplicadas, que conservam o acento de uma das partes componentes, passando o outro acento a ser secundário (Araujo, 2002, p. 74-79).
} 
de vogais médias-baixas em palavras que terminam em /u/ ou /r/: sédu ['sc.du]

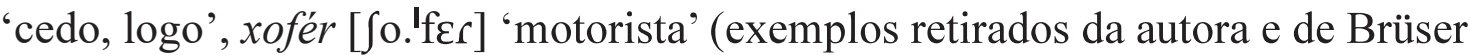
et al., 2002).

No que tange às vogais centrais do kabuverdianu, Lang et al. (2002, p. 62-63) mencionam que há alguns contextos em que /a/ é a forma preferida e outros em que a preferência incide sobre o $/ \mathrm{e} /$. Dentre os casos de primazia da forma /a/ estão: (i) ditongo [aw] em posição final de palavra: mau ['maw] 'mau', kularau [ku. le.'raw] 'colorau' (exemplo retirado de Brüser et al., 2002); (ii) sílabas tônicas em posição final terminadas em [s]: aliás [e.'ljas] 'aliás'. Já o /e/ é mais usado nos seguintes casos: (i) ditongo [ej] em final de palavra: papai [pe.'pej] 'papai'; (ii) sílabas tônicas em posição final terminadas em [ł]: sal ['seł] 'sal'; (iii) monossílabos que têm um onset complexo cujo elemento final é uma líquida: $f l a$ ['fle] 'falar', tra ['tre] 'tirar, extrair' (exemplos retirados desses autores). Assim, por conta dessa maior frequência de uma das formas em determinadas posições, poder-se-ia pensar que [a] e [e] são alofones de um mesmo fonema em distribuição complementar. Lang et al. (2002, p. 63), entretanto, afirmam que não há uma complementaridade absoluta entre as duas formas, havendo inclusive pares mínimos (como parti ['pes.ti] 'partir (1. quebrar, 2. repartir, 3. ir embora)' e parti ['par.ti] 'parte'; sabe ['se.bi] 'saber' e sabi ['sa.bi] '1. alegria, 2. agradável'), o que justifica considerar /a/ e /e/ como fonemas do kabuverdianu.

Quint (2000a, p.19-20), assim como Lang et al. (2002, p. 63), defende que, a despeito de não ser muito recorrente, a oposição entre as vogais centrais permite distinguir pares mínimos frequentemente usados na língua. Para ele, essa diferença entre /a/ e /e/ é privativa do kabuverdianu falado em Santiago, não aparecendo em outras variedades. Rodrigues (2007, p.150-151) também segue essa postura de considerar a existência de dois fonemas centrais na língua. Ela afirma que, na variedade santiaguense, em posição tônica, o [a] é mais comum, ao passo que, em posição átona, é mais frequente o [ə]. Para ela, em posição tônica, /a/ e /ə/ devem ser considerados fonemas, sendo a oposição neutralizada em posição átona (alofones posicionais).

Com relação à altura das vogais, Brüser et al. (2002, p.23), Lang et al. (2002, p.66-73) e Rodrigues (2007, p.205) mencionam que um aspecto particular do kabuverdianu consiste em permitir identificar a que classe gramatical uma determinada palavra (que tem na língua uma outra forma quase homófona) pertence a partir da altura de sua vogal tônica. De acordo com Lang (1994a, 1999 apud Rodrigues, 2007, p.205) esse processo teria um caráter mais morfofonológico do que fonológico. Em geral, em vocábulos terminados em $<\mathrm{a}>$, nos verbos, a vogal tônica será alta ou central/média-alta, ao passo que, nos nomes e adjetivos, ela 
será, majoritariamente, alta ou central/média-baixa. Há inclusive casos de pares mínimos (ou análogos) de verbo e substantivo ou adjetivo cuja oposição se dá somente com relação à altura de suas vogais tônicas. É o que se vê, por exemplo, em (1) (exemplos retirados de Lang et al., 2002, p.66-73)

(1) a. kareka [ke.'re.ke] 'ficar careca' e karéka [ke.'rc.ke] 'careca';

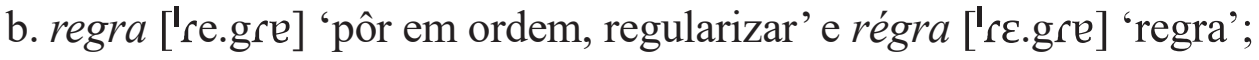

c. astia ['es.tje] 'hastear (bandeira)' e astia ['as.tje] 'bastão, vara';

d. raiba ['rej.be] 'ficar com raiva' e raiba ['raj.be] 'raiva';

e. dirota [di.'ro.te] 'derrotar' e diróta [di.'ro.te] 'derrota';

f. mostra ['mos.tre] 'mostrar(-se)' e móstra ['mos.tre] 'amostra, prova'.

Ainda no tocante à altura, segundo Brüser et al. (2002, p.23) e Lang et al. (2002, p.81), as vogais / $\varepsilon$, a, د/ só aparecem na sílaba tônica. Por causa disso, caso uma palavra que contenha um desses segmentos em posição acentuada sofra um processo de flexão ou derivação, com consequente deslocamento da sílaba tônica, as vogais centrais/médias-baixas são substituídas pelas suas correspondentes altas (/e, e , o/), como se vê em kabésa [ke.'be.se] 'cabeça' e kabesóna [ke.be.'so.ne] 'cabeça grande', laba ['la.be] 'lavar' e labado [le.'ba.du] 'tinha cantado', xikóti [Si.'ko.ti] 'chicote' e xikotada [ji.ko.'ta.de] 'chicotada' (exemplos retirados de Lang et al., 2002, p.81). Em posição átona final, a neutralização entre os graus de altura das vogais é ainda mais drástica, uma vez que, nessa posição, ocorrem apenas três vogais: [i], [5] e [u] (Brüser et al., 2002, p.23; Lang et al., 2002, p.82), como em skrebe ['skre. bi] 'escrever', kanta ['kẽ.te] 'cantar' e konko ['kõ.ku] '1. bater, 2. abanar' (exemplos retirados de Lang et al., 2002, p.82).

Quanto às sequências vocálicas em kabuverdianu, Lang et al. (2002, p.90-93) apontam a ocorrência de hiatos e ditongos. Dentre os hiatos, encontram-se os seguintes": (i) ['e.e]: fea ['fe.e] 'feia', rea ['re.e] 'areia', aldêa [eł.'de.e] 'aldeia', idêa [i.'de.e] 'ideia'5; (ii) ['i.e]: dia ['di.e] 'dia', kria ['kri.e] 'criar(-se)'; (iii) [e.'e]: ael [e.'eł] 'ele, ela (forma tônica, marcada)', aes [e.'es] 'eles, elas (forma tônica, marcada)'; (iv) [e.'u]: saúdi [se.'u.di] 'saúde', raúni [re.'u.ni] 'reunir'; (v): [e.'i]: raínha [re.'i.je] 'rainha' (exemplos retirados desses autores). Quanto aos ditongos, Lang et al. (2002, p. 90-93) afirmam que o kabuverdianu possui muitos ditongos orais e poucos nasalizados. Os primeiros podem ser tanto crescentes quanto decrescentes, apresentando o seguinte inventário /ej/, / $\mathrm{ej} /, / \mathrm{ej} /, / \mathrm{aj} /, / \mathrm{jj} /, /$

4. Segundo Lang et al. (2002, p. 90), o único hiato frequente no kabuverdianu seria [e.e]. Neste estudo, discorda-se dos autores, já que palavras como dia, ele(s), ela(s) são de alta frequência.

5. Nesses casos, as realizações com o hiato ['e.e] variam com formas com o ditongo [ej], como em feia ['feje]. 
oj/, /uj/; /iw/, /ew/, /عw/, /ew/ (só aparece em sílaba átona), /aw/\%; /je/, /je/, /je/, / ja/, /jo/, /jo/, /ju/; /wi/, /we/, /we/, /we/, /wa/, /wo/7.

Com relação aos ditongos nasalizados, nas variedades acroletais, ou seja, aquelas que recebem maiores influências do português, o número desses ditongos é maior. Já na variedade basiletal do kabuverdianu (o "crioulo fundo"), não aparecem com frequência e são sempre crescentes, havendo as seguinte possibilidades (Lang et al., 2002, p.93): /jeN/8 e /weN/9.

Quint (2003, p.17-18) aponta ainda os seguintes ditongos nasalizados: /jeN/, /joN/, /wiN/, /weN/ ${ }^{10}$. Nos ditongos nasalizados, a nasalidade aparece tanto na vogal como no glide, mas, em virtude de ser menos perceptível neste último, será marcada somente na vogal, núcleo da sílaba. Além disso, ditongos (orais) com as vogais /E/, /a/ e /د/ só ocorrem em sílabas tônicas (Lang et al., 2002, p.93).

\section{Sistema consonantal}

No tocante ao quadro consonantal, o kabuverdianu moderno apresenta vinte fonemas (Quadro $2^{11}$ ):

Quadro 2: Fonemas consonantais do kabuverdianu moderno

\begin{tabular}{|c|c|c|c|c|c|}
\hline--- & Labiais & Dentais & Alveopalatais & Palatais & Velares \\
\hline Oclusivas & $\mathrm{p} \mathrm{b}$ & $\mathrm{t} \mathrm{d}$ & & & $\mathrm{k} \mathrm{g}$ \\
\hline Fricativas & $\mathrm{f} \mathrm{v}$ & $\mathrm{s} \mathrm{z}$ & & $\int 3$ & \\
\hline Africadas & & & Tु $\mathrm{d} 3$ & & \\
\hline Nasais & $\mathrm{M}$ & $\mathrm{n}$ & & $\mathrm{n}$ & \\
\hline Líquidas & & $1 \mathrm{r}$ & & $\kappa$ & \\
\hline
\end{tabular}

Esse inventário fonológico difere do de Rodrigues (2007, p.144) somente

6. Nos dados dos autores, os ditongos /ow/ e /ow/ não foram documentados. Quanto ao último, aparece o onomatopaico póu! ['pəw] '1. interjeição onomatopaica que imita o ruído breve de um golpe, 2. emprega-se também para sugerir a rapidez de um movimento’.

7. Nos dados dos autores, o ditongo /wo/ não foi documentado.

8. Quanto ao ditongo /jaN/ (sugerido pelo exemplo kunfiansa [kũ.'fjã.se] 'confiança'), uma vez que, neste estudo, advoga-se que a oposição entre /a/ e /e/ é neutralizada em contextos nasalizados, considera-se somente a presença de $/ \mathrm{jeN} /$.

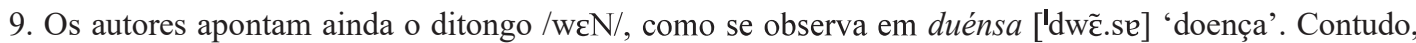
como, neste estudo, defende-se que ocorre neutralização entre as vogais médias em contextos nasalizados, apenas o ditongo /weN/ será considerado no âmbito fonológico.

10. O autor menciona ainda os ditongos $/ \mathrm{j} \varepsilon \mathrm{N} / \mathrm{e} / \mathrm{w \varepsilon N} /$, desconsiderados, neste estudo, em virtude da neutralização das vogais médias em contextos nasalizados.

11. Caso haja duas consoantes em sequência, a da esquerda é a surda e a da direita, a sonora (exceto nas líquidas, em que as duas são sonoras). Se a consoante estiver sozinha, ela é sonora. 
quanto à vibrante $(/ \mathrm{r} /)$, que a autora substitui pela simples $(/ \mathrm{r} /)$; ademais, ele se assemelha ao de Quint (2000a, p. 27-29), que considera a existência de 23 fonemas em kabuverdianu, acrescentando ao Quadro $2 / \mathrm{y}, \mathrm{j}$, w/. Esse quadro ainda é levemente diferente do apresentado por Brüser et al. (2002, p.23-24) e Lang et al. (2002, p. 94-95). Esses autores consideram como fonemas as oclusivas palatais $/ \mathrm{c} / \mathrm{e} / \mathrm{f} /$, ao invés das africadas alveopalatais $/ \mathrm{t} / \mathrm{e} / \mathrm{d} z /$. Essas divergências devem ser analisadas. No que diz respeito às oclusivas palatais, Lang et al. (2002, p. 107) afirmam que esses segmentos, stricto sensu, seriam africados e não oclusivos. Assim, eles seriam foneticamente mais complexos do que as demais oclusivas. A despeito dessa maior complexidade, esses autores sustentam o uso das representações /c/ e /f/, em lugar de /t $\mathrm{j} /$ e /dz/, para enfatizar o ponto de articulação realmente palatal dessas consoantes, enquanto que, nas fricativas $/ \mathrm{g} / \mathrm{e} / \mathrm{z} /$, ele está mais próximo dos alvéolos. Considerando que as oclusivas palatais e as africadas alveopalatais não são correspondentes e que as primeiras são raras nas línguas do mundo, este estudo segue o posicionamento de Rodrigues (2007, p.144), considerando que o kabuverdianu possui consoantes africadas.

Quanto à vibrante, Rodrigues (2007, p.145) considera que [r] (encontrado em Santiago e Fogo) e [R] (usado em Santo Antão e São Vicente) seriam variantes de outros fonemas. A autora traz a opinião de Lopes da Silva (1984, p.105 apud Rodrigues, 2007, p.145), que reconhece que, em Santiago, a alternância entre as vibrantes em posição intervocálica é comum. A opção de considerar a vibrante simples como fonema é justificada por Rodrigues (2007, p.145) pelo fato de esta ocorrer em maior número de contextos e com maior frequência do que a vibrante múltipla, sendo esta um alofone de / $/ \mathrm{em}$ alguns contextos. Sobre esse assunto, Lang et al. (2002, p.108-109) afirmam que, em kabuverdianu, "o número de toques da ponta da língua contra os alvéolos não é fonologicamente distintivo. Ocorrem realizações com um, dois, três e, especialmente em pronúncias enfáticas, até mais toques.”. Assim, segundo esses autores, existe uma variação entre $[r]$ e $[r]$, havendo contextos em que uma das formas é preferida. Salvo os casos de ênfase, $o[r]$ aparece com mais frequência em posição inicial de palavras e como segundo membro de um cluster, como $<b r$, $t r\rangle^{12}$, entre outros. Já em posição de coda (seja medial ou final), o [ $c$ é mais usado. Em posição intervocálica, a escolha por uma forma ou por outra varia de acordo com o falante. Ainda com relação às vibrantes, Clements (2014) analisa os róticos em algumas línguas crioulas de base ibérica da região atlântica (kabuverdianu, kriyol de Guiné Bissau e Casamança, santome, angolar, palenquero e papiamentu) e da Ásia (crioulos indo-portugueses de Diu, Damão e Korlai, e zamboanguenho) e advoga que as 
variedades de português e de espanhol que atuaram como línguas de superstrato muito provavelmente possuíam a distinção entre $/ \mathrm{f} / \mathrm{e} / \mathrm{r} /$. Além disso, segundo o autor, é esperado que os róticos das línguas de substrato (as línguas maternas dos escravos) terminem sendo transferidos para o pidgin ou crioulo recém-formado (Clements, 2014, p.346-347). Ao analisar as condições que geraram a distribuição dos róticos nas referidas línguas crioulas, Clements (2014, p.327-348) leva em consideração fatores como o número de línguas envolvidas no contato, a presença de uma cultura escravocrata e/ou de plantation, a ocorrência de contato com a língua lexificadora e os róticos presentes nas línguas de substrato. Em sua análise, o autor conclui que nenhum dos crioulos atlânticos analisados apresenta oposição fonêmica entre / $/$ e e $/ \mathrm{r}$. Esse quadro confirma a afirmação de Ladefoged \& Maddieson (1996, p.237) de que a maior parte das línguas do mundo possui apenas um rótico em seus quadros fonológicos. No caso do kabuverdianu, a ausência da distinção poderia ser explicada por dois fatores: (i) o cenário linguístico heterogêneo (apesar da presença constante do português), o que dificultaria a retenção dos dois róticos presentes na língua-alvo; (ii) a ausência de oposição entre / $/$ e e $/ \mathrm{r} /$ no wolof, principal língua dos escravos de Cabo Verde (Clements, 2014, p. 351).

Com relação à nasal velar ([y]), Rodrigues (2007, p.145) afirma que essa consoante não teria um estatuto fonológico. Trazendo uma postura diversa, segundo Lang et al. (2002, p.96-98), Quint (2000a, p.27-29) defende a existência do fonema $/ \mathrm{y} /$ em kabuverdianu. Para sustentar seu posicionamento, o autor aponta a existência de palavras iniciadas pela consoante nasal velar seguida por vogal. Nesses casos, o $/ \mathrm{y} /$ se opõe às demais consoantes nasais $(/ \mathrm{m}, \mathrm{n}, \mathrm{n} /$ ), razão pela qual recebe o estatuto de fonema. Todos os exemplos (trazidos pelo autor) que se iniciam por esse som têm seu étimo em alguma língua africana, não podendo ser atribuídos ao português. Para Lang et al. (2002, p.96-98), é legítimo que um fonema $/ \mathrm{y} /$ realmente exista em algumas variedades mais isoladas do kabuverdianu falado em Santiago. Contudo, apoiando-se nos fatos de nenhuma das descrições do século XIX mencionar a existência de um fonema $/ \mathrm{y} /$ e de seus informantes pronunciarem as palavras que começariam por esse fonema de outra forma, prescindindo do mesmo, os autores não incluem o $/ \mathrm{y} /$ no quadro de fonemas da língua - mesma posição de Brüser et al. (2002, p.24) -; ele aparece como um fone, sendo usado opcionalmente em posição final de palavra quando precedido por uma vogal nasal ou quando há uma oclusiva nasalizada.

Por fim, este estudo considera os glides ([j, w] ) como alofones, e não como fonemas, uma vez que não existe em kabuverdianu oposição entre eles e as vogais altas correspondentes (/i, u/). Além dessa lista de consoantes, Brüser et al. (2002, 
p.23-24) e Lang et al. (2002, p.94-96, 98-99) apontam a existência de consoantes (pré-)nasalizadas correspondentes a cada uma das consoantes orais: $/ \mathrm{Np}, \mathrm{Nb}, \mathrm{Nt}$, $\mathrm{Nd}, \mathrm{Nk}, \mathrm{Ng}, \mathrm{Nf}, \mathrm{Nv}, \mathrm{Ns}, \mathrm{Nz}, \mathrm{N}\}, \mathrm{Nz}, \mathrm{Nt} \int, \mathrm{Ndz}, \mathrm{Nl}, \mathrm{Nr}, \mathrm{N} K /{ }^{13}$, acrescentando 17 fonemas ao kabuverdianu. Os autores afirmam que ainda não encontraram nenhuma ocorrência da correspondente nasalizada da lateral palatal (/NK/), o que leva a uma necessidade de confirmação de sua existência. Já a vibrante nasalizada $(/ \mathrm{Nr} /)$ até o momento só apareceu em posição medial, como em ónra /'DNre/ 'honra'. Grande parte dessas consoantes nasalizadas tem origem em palavras do português com uma vogal seguida de consoante nasal na coda, mas precisamente os prefixos $<$ em-, en-> ([ẽ]) e, em menor escala <in-, im-> ([1]) (Lang, 2014, p.156) ${ }^{14}$. Certamente, a vogal foi apagada por restrições de palavras que começam com vogal, comum em línguas do oeste da África, como o wolof (Lang, 2014, p.158-160).

No âmbito fonético, em posição inicial, as consoantes nasalizadas são segmentos complexos, compreendendo uma consoante oral antecedida por uma nasal homorgânica (ou seja, que possui o mesmo ponto de articulação): [mp, mb, nt, nd, yk, yg, mf, mv, ns, nz, nf, n3, nt $\int$, ndz, nl, nr] (Brüser et al., 2002, p.23-24; Lang et al., 2002, p.109-110). Segundo Lang et al. (2002, p.51-60, 109-110), em posição interna de palavra, os fonemas consonânticos nasalizados só aparecem depois de uma vogal. Esses autores apontam ainda que, nessa posição, a representação da nasalidade varia de acordo com a natureza do fonema consonântico. Se a consoante for uma oclusiva, africada ou lateral, a nasalidade aparece sob a forma de uma consoante nasal homorgânica. Caso a consoante seja uma fricativa ou a vibrante, a nasalidade aparece apenas na vogal. Neste estudo, considera-se que, independentemente do tipo de consoante, em posição medial, em grande parte dos casos, apenas a vogal será nasalizada (e a consoante será oral), como em kanpia ['kẽ.pje] 'passear, vadiar', kanba ['kẽ.be] '1. entrar, 2. desaparecer', kanta ['kẽ.te] 'cantar', ronda ['rõ.de] 'ronda', konko ['kõ.ku] '1. bater, 2. abanar', disdongu [dis.'dõ.gu] 'fingir-se de surdo, não responder', kunfia ['kũ.fje] 'confiar', konvérsa [kõ.'ver.se] 'conversa', pensa ['pẽ.se] 'pensar', onzi ['õ.zi]

13. Os autores representam essas consoantes nasalizadas com um til sobre a consoante, representação que, neste estudo, é considerada inadequada. Esse mesmo posicionamento é defendido por Couto (2005, p.134135): "Mesmo a gramática não tendo sido o objetivo do Dicionário, temos aí um bom tratamento da fonologia coboverdiana [sic], mesmo que se possa discordar de algumas interpretações, como a das prenasalizadas [sic] e, sobretudo, de [sic] sugestão de como representá-las, ou seja, com um til sobre cada consoante. Além disso, poder-se-ia discutir se realmente há consoantes prenasalizadas [sic] em caboverdiano em nível subjacente.”

14. Dos 120 exemplos mencionados pelo autor (Lang, 2014, p.152-156), apenas 6 não apresentavam, em português, nenhuma nasal na primeira sílaba. São eles: (i) nbera ['mbe.re] 'berrar, gritar' (< português berrar); (ii) ndoxa ['ndo.fe] 'adoçar, ficar doce' (< português (a)doçar); (iii) ndjarga ['ndzar.ge] njarga ['nzar.ge] 'ilharga' (< português ilharga); (iv) ndjudjun [ndzu.'dzũ(y)] njujun [nzu.'zũu(y)] 'jejum' (< português jejum); (v) nfórka ['mfjR.ke] 'forca' (< português forca); (vi) ntola ['nto.le] 'atolar(-se)' (< português (a)tolar ). 
'onze', konxe ['kõ.fi] 'conhecer', lonji ['lõ.zi] 'longe', santxu ['sẽ.tfu] 'macaco (grande)', djondjo ['dzõ.dzu] 'enlaçar, ligar', konloia [kõ.lo.je] 'conluiar, conspirar', onra ['õ.re] 'honra' (exemplos retirados desses autores). Em posição medial, há ainda a possibilidade de a consoante nasal ser pronunciada (com a vogal precedente nasalizada ou não). Contudo, nesse caso, a consoante nasal pertenceria à sílaba anterior (estando relacionada à vogal), a exemplo de kanpia ['kẽm.pje] ['kem.pje] ${ }^{15}$ 'passear, vadiar'. Em posição final, não é necessário discutir como se dá a realização da nasalidade, uma vez que as consoantes nasalizadas não aparecem nesse contexto (Lang et al., 2002, p.110).

Segundo Lang et al. (2002, p.51-60, 98-99), a existência dos fonemas consonânticos nasalizados no kabuverdianu não encontra consenso entre os estudiosos, havendo aqueles que não consideram esses segmentos como pertencentes ao quadro fonológico da língua. Rodrigues (2007, p. 172-175), por exemplo, alega que, nesses casos, fonologicamente, há uma consoante oral precedida por um arquifonema nasal /N/. Quint (2000a, p.32-33) também sugere que essas consoantes são formadas por dois elementos e ocorrem apenas em posição inicial absoluta, uma vez que, no interior da palavra, a consoante nasal transmite sua nasalidade para a vogal precedente e depois é apagada. Lang et al. (2002, p.51-60, 98-99) sustentam, por outro lado, que as consoantes nasalizadas devem realmente ser vistas como fonemas da língua. Para eles, a existência de pares mínimos e análogos justifica a inclusão das consoantes nasalizadas no inventário fonológico do kabuverdianu. Dentre esses pares mínimos e análogos, citam-se (exemplos retirados de Lang et al., 2002, p.104-106) ${ }^{16}$ :

(2) a. /p/e e/Np/:para ['pa.re] 'parar'e npara ['mpa.re] '1. apanhar, 2. amparar, 3. acolher';

b. /b/ e /Nb/: bala ['ba.le] '1. bala, 2. vala' e nbala ['mba.le] 'embalar, ganhar velocidade';

c. /t/ e /Nt/: ton ['tõ(y)] 'tão, muito' e nton ['ntõ(y)] 'então';

d. /d/ e /Nd/: dretu ['dre.tu] '1. direito, correto, bem, 2. diretamente' e ndreta ['ndre.te] '1. endireitar-se, 2. direita (adjetivo)';

e. /k/ e /Nk/: kanta ['kẽ.te] 'cantar' e nkanta ['ykẽ.te] 'encantar(-se)';

f. /g/ e /Ng/: gana ['ga.ne] 'gana, desejo' e ngana ['yga.ne] 'enganar(-se)';

g. /f/ e /Nf/: fia ['fje] ['fie] '1. enfiar, 2. dar crédito, vender a crédito, fiar' e nfia ['mfje] 'enfiar (-se)';

15. Na grafia, a nasalidade é indicada sempre com $<$ n $>$ mesmo em contextos que precedem $\langle p>$ e $<b>$; assim, o $<$ n $>$ não marca uma natureza alveolar/dental para a consoante nasal.

16. Os exemplos seguintes só apresentam consoantes nasalizadas em início de palavra, já que, neste estudo, defende-se que elas não ocorrem em posição medial. 
h. /v/ e /Nv/: vira ['vi.re] '1. virar (1.1 voltar-se, 1.2 transformar-se), 2. vira (dança popular portuguesa)' e nvira ['mvi.re] 'ter raiva de alguém a ponto de tentar prejudicá-lo';

i. /s/ e /Ns/: sodadi [so.'da.di] 'saudade' e nsodadu [nso.'da.du] '1. distraído, 2. de repente';

j. /z/ e /Nz/: zini ['zi.ni] 'ressoar, ecoar' e nzami ['nza.mi] 'exame, prova';

k. / / e /N $/$ : xuta ['fu.te] 'chutar' e nxuta ['nfu.te] 'secar, ficar enxuto/seco';

1. /3/ e /Nz/: jura ['zu.re] 'jurar' e njuria ['nzu.rje] '1. insultar, ofender, 2. ofensa, injúria';

m. $/ \mathrm{t} \int /$ e $/ \mathrm{Nt} \int /:$ txada ['t $\left.\int \mathrm{a} . \mathrm{de}\right]$ '1. sítio plano, planície, 2. grande quantidade' e $n t x a d u$ ['nt $\left.\int \mathrm{a} . \mathrm{du}\right]$ 'inchado';

n. /dz/ e /Ndz/: djuga ['dzu.ge] '1. jogar, 2. arremessar' e ndjudjun [jdzu.'dzũ (y)] 'jejum';

o. /1/ e /N1/: lion [li.'õ(y)] 'leão' e nliona ['nljo.ne] 'irritar-se'.

Neste estudo, considera-se que as consoantes nasalizadas são realizações fonéticas, não tendo estatuto fonológico. Três fatores embasam essa postura: (i) em geral, as línguas crioulas possuem um quadro consonantal (e vocálico) com menos elementos do que as línguas que lhes deram origem (Klein, 2006, p.6-7). Assim, assumir as consoantes nasalizadas como sendo fonemas do kabuverdianu dobraria o número de consoantes com relação à língua lexificadora (o português), o que não é usual nos crioulos; (ii) essas consoantes só aparecem em início de palavra, sendo resultado da aférese da vogal inicial em vocábulos provenientes do português; (iii) uma evidência mais confiável da existência dessas consoantes seria a existência de pares mínimos com as correspondentes orais na mesma classe de palavra (por exemplo, dois nomes ou dois verbos), o que, de uma maneira geral, não é verificado, sendo os membros do par pertencentes a classes diferentes (muitas vezes, um verbo e um nome).

Além dos segmentos consonânticos já discutidos, a série das fricativas sonoras e a consoante lateral palatal também devem ser analisadas mais detidamente (Lang et al., 2002, p.99-102). Para os autores, é possível que, inicialmente, o kabuverdianu não possuísse os fonemas $/ \mathrm{v}, \mathrm{z}, 3, K^{17}$. À exceção de [z], nenhum desses sons aparecia sequer como variantes de outros fonemas condicionadas pelo contexto. Assim, no começo da colonização de Cabo Verde, pode-se conjecturar que, ao se depararem com alguma forma do português que tinha uma dessas consoantes, os falantes do kabuverdianu realizavam-nas como [b, s, $\left.\int, d_{3}\right]$, respectivamente. Com o passar do tempo, as substituições deixaram de ser feitas

17. Lang et al. (2002, p.99-102) defendem esse cenário com relação às fricativas sonoras e à lateral palatal, mas não apresentam evidências que sustentem tal hipótese. 
e as fricativas sonoras e o $/ K /$ passaram ao quadro fonológico da língua, sobretudo a partir de empréstimos do português.

Com relação ao /v/, pode-se dizer que ele já está completamente integrado ao sistema, havendo, para grande parte dos falantes, vocábulos que devem ser pronunciados com [b] (como bitxu ['bi.tsu] 'bicho, animal' e sabidu [se.'bi.du] '1. esperto, astuto, 2. energicamente'), outros que possuem [v] (a exemplo de vingansa [ṽi.'gẽ.se] 'vingança' e arvi ['ar.vi] arvri ['ar.vri] 'árvore') e ainda alguns em que há variação entre [b] e [v] (por exemplo, fabor [fe.'bor] favor [fe.'vor] 'favor' e benénu [be.'nع.nu] venénu [ve.'nc.nu] 'veneno') (exemplos retirados desses autores e de Brüser et al., 2002). É possível também que, ainda hoje, para algumas variedades da língua e mesmo para alguns falantes, não haja oposição entre [b] e [v]. Quanto ao /z/, é possível que, desde os primórdios do kabuverdianu, já existisse um $[\mathrm{z}]$ como alofone de /s/ diante de consoante sonora. Com o passar dos anos, começa a ocorrer [z] também em contextos antes reservados ao /s/, como em início de palavra e posição intervocálica.

Lang et al. (2002, p.100) defendem que houve, desse modo, a fonologização do [z] (que ganhou estatuto de fonema). Mesmo hoje, existem formas em que há variação entre [s] e [z], como fase ['fa.si] faze ['fa.zi] 'fazer' e simóla [si.'ms. le] sumóla [su.'mo.le] zimóla [zi.'mっ.le] zumóla [zu.'mっ.le] 'esmola'. As formas com [s] são características do "crioulo fundo" (variedade que mais se distancia do português), ao passo que o [z] aparece nas variedades que estão em um contato maior com o português ("crioulo leve"), sendo mais semelhante a ele. Já no que diz respeito ao fonema / $3 /$, ele aparece tanto em empréstimos recentes do português (como jóia ['zว.je] 'joia(s)' e jésu ['zE.su] 'gesso'), como em palavras provavelmente mais antigas (a exemplo de finji ['fi.zi] 'fingir' e ranja ['rẽ.ze] 'arranjar'), havendo ainda casos em que as formas com [S] e [3] variam: oxi ['o. Si] $\sim$ oji ['o.zi] 'hoje' e grexa ['gre.fe] igreja [i.'gre.ze] 'igreja' (exemplos retirados de Lang et al., 2002,p. 101). Por fim, no tocante ao $/ K /$, considerando que, em obras antigas, são raras as palavras com $<\mathrm{lh}>$, é possível conjecturar que as formas com o fonema lateral palatal são empréstimos recentes oriundos do português ${ }^{18}$. É o caso, por exemplo, de ilha ['i.Ke] 'ilha' e mulher [mu.'Ker] 'mulher', formas que coexistem, respectivamente, com djar ['dzar] e mudjer [mu.'dzer] mudjê [mu.'dze], provavelmente mais antigas na língua (exemplos retirados de Lang et al., 2002, p.101).

18. Esse mesmo posicionamento é defendido por Rougé (1994, p.140), que afirma que os vocábulos do português que possuem $/ K /$ são nativizados com $/ \mathrm{j} /$, a exemplo de paja e miju (oriundos, respectivamente, de palha e milho). 


\section{Estrutura silábica}

De acordo com Lang et al. (2002, p. 111), a despeito de possuir uma grande quantidade de fonemas consonantais, o kabuverdianu (especialmente a variedade de Santiago) permite um número restrito de combinações entre eles. Não existem consoantes geminadas, os clusters consonantais com dois ou três elementos são pouco comuns e não ocorrem combinações de quatro ou mais consoantes. Além disso, segundo os autores, há uma predominância de sílabas abertas (terminadas em vogal, sem a coda preenchida) e de estruturas silábicas CV.CV(...).

Quanto aos elementos que podem ser encontrados em cada uma das posições silábicas na variedade geral do kabuverdianu, segundo Rodrigues (2007, p.158, $163,179)$, o onset pode ser preenchido por até três elementos consonantais - o que contraria a assunção de Lang et al. (2002, p.111) de que os clusters não são muito frequentes. Já o núcleo deve ser ocupado obrigatoriamente por uma vogal, admitindo ainda um segmento vocálico marginal (o glide), que pode anteceder ou seguir a vogal nuclear a depender do tipo de ditongo. Por fim, na coda, pode haver apenas um elemento. Como poderá ser observado com mais detalhes na subseção seguinte, a estrutura silábica adotada neste estudo difere levemente no que diz respeito à posição de núcleo. Uma vez que os glides não seriam elementos de natureza vocálica, eles estariam localizados no onset ou na coda (no caso de ditongos crescentes e decrescentes, respectivamente), sendo a posição de núcleo ocupada por apenas um elemento vocálico. Assim, em suma, de forma esquemática, a estrutura da sílaba em kabuverdianu seria a seguinte:

Os elementos entre parênteses são opcionais. A combinação das consoantes no onset não é livre: por exemplo, C1 e C3 não se combinam sem restrições, já que, para que $\mathrm{C} 3$ ocorra, $\mathrm{C} 2$ também deve estar presente. Além disso, caso haja $\mathrm{C} 2$, certamente ela é um subconjunto de $\mathrm{C} 1 \mathrm{e}$, se houver $\mathrm{C} 3$, os elementos que podem estar em combinação são muito restritos. Assim, caso haja duas consoantes no onset, se a primeira for uma oclusiva (/p, b, t, d, k, g/) ou /f, v/, a segunda

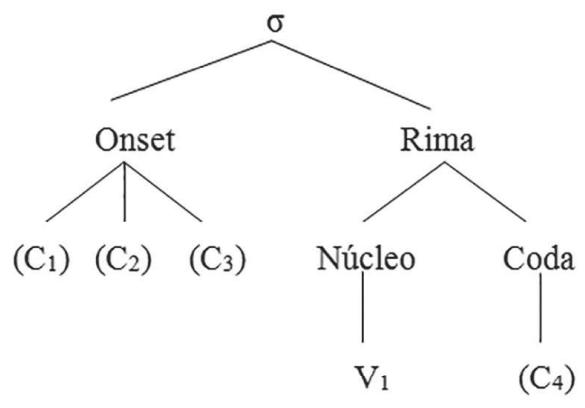

é obrigatoriamente uma líquida (/1,r/) ou um glide ([j, w]); já se $\mathrm{C} 1 \mathrm{for} / \mathrm{s} /, \mathrm{C} 2$ é uma oclusiva, /f/ ou $/ \mathrm{m} /$. Nas combinações de três consoantes, por seu turno, $\mathrm{C} 1$ 
deve ser /s/, C2, uma das consoantes surdas (/p, t, k, f/), e C3, uma das líquidas ou um glide. Após essas informações gerais sobre a sílaba no kabuverdianu, as subseções seguintes são dedicadas à discussão mais detalhada sobre quais elementos vocálicos ocupam o núcleo e quais segmentos consonantais podem estar no onset e na coda.

\subsection{Núcleo}

A posição de núcleo em kabuverdianu pode ser preenchida por segmentos vocálicos (as vogais orais e suas correspondentes com o traço [+ nasal]) e pela consoante nasal quando se trata do pronome de $1^{\text {a }}$ pessoa do singular ${ }^{19}$ (exemplos retirados de Brüser et al., 2002; Lang et al., 2002, p.61; Rodrigues, 2007, p.151, 153):

(3) a. /i/ - idadi [i.'da.di] 'idade' e pidi ['pi.di] 'pedir';

b. /e/ - ekipa [e.'ki.pe] 'equipe, time' e leti ['le.ti] 'leite';

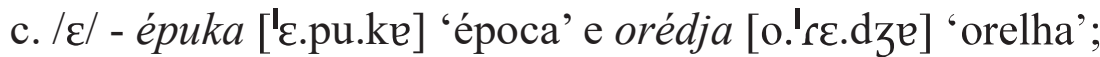

d. /e/ - abala [e.'ba.le] 'comover, impressionar' e odja ['o.dze] 'olhar';

e. /a/ - ábitu ['a.bi.tu] 'hábito' e sidadi [si.'da.di] 'cidade';

f. /J/ - óbu ['כ.bu] 'ovo' e pórta ['pos.te] 'porta';

g. /o/ - obriga [o.'bri.ge] 'obrigar' e notisia [no.ti.sje] 'notícia(s)';

h. /u/ - úniku ['u.ni.ku] 'único' e guvérnu [gu.'ves.nu] 'governo';

i. [i] - insétu [1.'sc.tu] 'inseto' e tinji ['ti.zi] 'tingir';

j. [ẽ] - enfin ['ẽ.fi(y)] 'enfim' e sensason [sẽ.se.'sõ(y)] 'sensação';

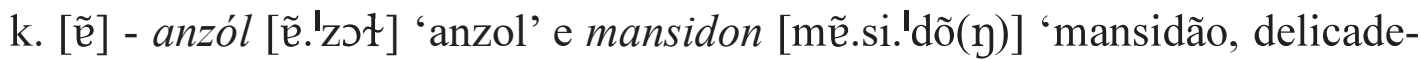
za';

1. [õ] - ónradu [õ.'ca.du] 'honrado' e konviti [kõ.'vi.ti] 'convite';

m. [ũ] - un ['ũ(y)] 'um, uma' e bagunsa [be.'gũ.se] 'bagunça, desordem';

n. /N/ - o ponto de articulação da nasal silábica assimila o da consoante seguinte, encontrando-se as seguintes realizações: (i) [m] diante de consoante labial; (ii) [m] quando seguida de consoante labiodental; (iii) [n] no caso de a consoante seguinte ser dental; (iv) [n] quando a consoante seguinte for palatal; (v) [y] diante de consoante velar, de vogais e em final de palavra.

Quanto aos glides ([j, w]), não há um consenso sobre sua natureza: se são vogais (e, portanto, ocupam o núcleo) ou consoantes (e, por conseguinte, estão no onset ou na coda). Rodrigues (2007, p.149-151) aponta essa ausência de consenso e, em seu estudo, considera que os glides, que formam ditongos crescentes ou decrescentes, são vogais e, assim, localizam-se no núcleo da sílaba. Essas

19. Uma análise mais aprofundada - como realizado por Agostinho (2015, p.69-74) para o lung'ie - deve ser feita a fim de descobrir se, no caso das consoantes pré-nasalizadas, a consoante nasal é silábica ou não. 
"semivogais" aparecem inclusive como fones no quadro fonológico das variedades estudadas pela autora: Santiago, Fogo, Santo Antão e São Vicente. Lang et al. (2002, p.90-91) também concebem o glide como um elemento vocálico, que acompanha uma vogal para formar um ditongo, gerando, então, um núcleo ramificado. Contudo, no decorrer da discussão, os autores apresentam uma postura dúbia no que diz respeito ao tratamento dos glides a depender do tipo de ditongo. Nos casos de ditongos decrescentes, a segunda vogal recebe o nome de semivogal e é representada por [i] ou [u] (no Alfabeto Fonético Internacional (IPA), [I] ou [U] ], respectivamente). Já quando se tem ditongos crescentes, a primeira vogal é denominada como semiconsoante e corresponde a [j] ou [w].

\subsection{Onset}

Ocupando a posição de onset simples (constituído por apenas uma consoante) em kabuverdianu, tanto no começo quanto no meio da palavra, é possível encontrar praticamente todos os segmentos do inventário consonantal do kabuverdianu, exceto $/ K /$, que só aparece em posição medial (Lang et al., 2002, p.112-113). Os glides também podem ocorrer no onset. Em (4), aparecem exemplos (retirados de Lang et al., 2002, p.95-96 e 103-104; Brüser et al., 2002) das consoantes na posição de onset simples (as consoantes em onset estão sublinhadas na representação fonética):

(4) a. Oclusivas (/p, b, t, d, k, g/): pai ['pej] 'pai', barba ['bar.be] 'barba', totis ['to.tis] 'nuca, toutiço', dia ['die] 'dia', kasa ['ka.se] '1. casar(-se), 2. caçar, 3. prender, capturar, 4. casa', galu ['ga.lu] 'galo';

b. Fricativas (/f, v, s, z, $\int, 3 /$ ): fólga ['foł.ge] 'folga (1. descanso, 2. espaço)', próva ['pro.ve] 'prova', sala ['sa.le] 'sala', zóna ['zo.ne] 'zona', xa ['Ja] 'chá', juis ['zwis] '1. juízo, 2. juiz';

c. Africadas (/t $\left.\int, \mathrm{dz} /\right)$ : txon ['t $\left.\mathrm{t} \mathrm{o}(\mathrm{y})\right]$ 'chão', djuguta [dzu.'gu.te] 'lutar por alguma coisa, esforçar-se';

d. Nasais (/m, n, J/): mai ['mej] 'mãe', nada ['na.de] '1. nadar, 2. nada, de modo nenhum', nho ['no] '(o) senhor';

e. Líquidas (/l, r, K/): larga ['lar.ge] 'largar', rabola [re.'bo.le] 'rebolar', repolhu [re.'po.Ku] 'repolho';

f. Glides ([j, w]): iati ['ja.ti] 'iate', uiski ['wis.ki] 'uísque'.

Além disso, o kabuverdianu admite ainda a ocorrência de onsets complexos, formados por duas ou três consoantes (Quint, 2000a, p.30-31; Lang et al., 2002, p.104-106 e 112-114; exemplos retirados desses autores e de Brüser et al., 2002):

(5) Clusters com duas consoantes (CC ou $C G$ ): na primeira posição do cluster, aparece uma das seguintes consoantes: /p, b, t, d, k, g, f, v, s/. Podem ocupar 
a segunda posição uma consoante líquida (/l, r/), um glide ([j, w]) ou /p, b, t, d, $\mathrm{k}, \mathrm{g}, \mathrm{f}, \mathrm{m} /$ (apenas no caso de o primeiro membro do cluster ser/s/). Os clusters que possuem /s/ como primeiro membro ocorrem apenas em posição inicial (Rodrigues, 2007, p.176). Já o cluster /vr/ aparece somente em posição medial. Os demais ocorrem em posição inicial ou medial. Ademais, o/s/ inicial dos clusters é pronunciado como [z] caso preceda uma consoante sonora ([zb], [zd], [zg], [zm]) (Lang et al., 2002, p.111, 113). As combinações possíveis entre esses elementos são (na transcrição fonética, os clusters estão sublinhados):

a. /pl, pr/, [pj, pw]: planta ['plẽ.te] 'planta', prende ['prẽ.di] '1. aprender, 2. prender', rapia ['ra.pja] 'arrepiar(-se)', barapuada [be.re.'pwa.de] 'paulada, cacetada';

b. /bl, br/, [bj, bw]: blóku ['blo.ku] 'bloco de betão', brasu ['bra.su] '1. braço, 2. medida de profundidade $(1,83 \mathrm{~m})$ ', sibia [si.'bje] 'assobiar', buati ['bwa.ti] 'boate, discoteca';

c. /tr/, [tj, tw]: treme ['tre.mi] 'tremer, estremecer', muntia ['mũ.tje] '1. caçar, 2. amontoar(-se)', tuadja ['twa.dze] 'toalha, pano';

d. /dr/, [dj, dw]: dribla ['dri.ble] 'driblar', diabu ['dja.bu] 'diabo', duedu ['dwe. $\mathrm{du}]$ 'dilacerante, doloroso, triste';

e. /kl, kr/, [kj, kw]: klaru ['kla.ru] 'claro, nítido', kre ['kre] '1. querer, desejar, 2. acreditar, 3. porventura, talvez', kiabus "Abelmoschus esculentus" ['kja.bus] 'quiabo', kua ['kwe] 'coar, filtrar';

f. /gl, gr/, [gj, gw]: glin-glin-glin [gli.gli.'gగi(y)] onomatopeia (os autores não trazem um significado e esse vocábulo não aparece no dicionário de Brüser et al., 2002), grandi ['grẽ.di] 'grande', gia ['gje] 'guiar, conduzir, andar de', mingua ['mĩ.gwe] 'minguar, diminuir';

g. /fl, fr/, [fj]: flor ['flor] 'flor', frazi ['fra.zi] 'frase', purfia ['pur.fje] 'teimar, insistir';

h. /vr/, [vj, vw]: livru ['li.vru] 'livro', aliviu [e.'li.vju] 'alívio', nevueru [ne.'vwe.ru] 'nevoeiro';

i. /sp, sb, st, sd, sk, sg, sf, sm/, [sj, sw]: spértu ['sper.tu] 'esperto', sbanja

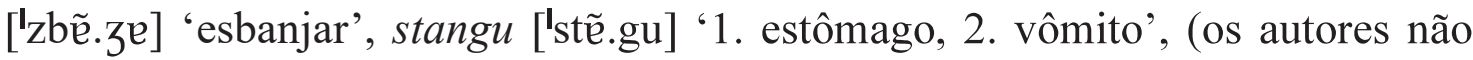
trazem exemplos de /sd/, nem aparecem casos em Brüser et al., 2002), skese ['ske. se] 'esquecer(-se)', sgota ['zgo.te] 'esgotar(-se)', sfaimadu [sfej.'ma.du] 'esfomeado', smaia ['zma.je] 'desmaiar', pasia ['pa.sje] 'passear', suadju ['swa.dzu] 'piso, soalho';

j. [zj]: buziu ['bu.zju] 'búzio';

k. [lj, lw]: mobilia [mo.'bi.lje] 'mobília', lua ['lwe] 'lua';

1. [rj, rw]: mimória [mi.'mo.rja] 'memória', ruina ['rwi.ne] 'arruinar, destruir'. 
(6) Clusters com três consoantes (CCC ou CCG) (só ocorrem em posição inicial $)^{20}$ :

a. /Npr, Nbr, Ntr, Ndr, Nkr, Ngr, Nfl, Nfr/: nprista ['mpris.te] '1. emprestar, 2. tomar emprestado', nbrabise [mbre.'bi.si] 'tornar-se agressivo', ntrega ['ntre.ge] 'entregar', ndreta ['ndre.te] '1. endireitar-se, 2. direita, correta', nkrusa ['ykru. se] 'cruzar', ngrosa ['ygro.se] 'crescer', nflema ['mfle.me] 'inflamar-se, inchar', nfrakise [mfre.'ki.si] 'enfraquecer';

b. /spl, spr, str, skr, sfr/, [spj, skw]: splika ['spli.ke] 'explicar', spremi ['spre. mi] 'espremer(-se)', stréla ['strc.le] 'estrela', skrabu ['skra.bu] 'escravo', sfrega ['sfre.ge] 'esfregar', spia ['spje] 'observar, olhar, espiar', skwa ['skwe] 'escoar, escorrer'.

\subsection{Coda}

De acordo com Brüser et al. (2002, p.24) e Lang et al. (2002, p.112), a posição de coda, no meio ou no fim de palavra, no kabuverdianu de Santiago, só pode ser ocupada pelas consoantes /1, r, s/, não havendo casos de clusters nessa posição ${ }^{21}$.

Além desses segmentos, Quint (2000a, p.29) menciona ainda a ocorrência dos glides ([j, w]) nessa posição. Os exemplos em (7) (retirados de Quint, 2000a, p.29; Lang et al., 2002, p.112) trazem os elementos que podem aparecer na coda (as consoantes em coda estão sublinhadas na transcrição fonética):

(7) a. /l/: mel ['meł] 'mel';

b. /r/: lugar [lu.'gar] 'lugar';

c. /s/: mes ['mes] 'mês', dizasaix [di.ze.'sej\}] 'dezesseis';

d. [j]: mai ['mej] '1. mãe, 2. (num jogo de crianças) local em que se está seguro, 3. árvore que começa a dar frutos';

e. [w]: kau ['kaw] '1. lugar, 2. propriedade, campo, 3. situação, 4. tempo atmosférico'.

Além dos segmentos listados em (7), as consoantes nasais também podem ocupar a posição de coda (como em kanpia ['kẽm.pje] 'passear, vadiar', kanta ['kẽn.te] 'cantar'). Opcionalmente, no âmbito fonético, pode ocorrer a transmis-

20. Aqui também são listados os clusters com consoantes nasalizadas, já que, assim como Rodrigues (2007: $172,175,177)$, considera-se que tais elementos, do ponto de vista fonológico, constituem uma combinação do arquifonema nasal + consoante oral.

21. Apesar de Quint (2000a, p.29) afirmar que o kabuverdianu moderno realiza o /1/ como [1] em todas as posições, mesmo em coda medial ou final, neste estudo, considera-se que o /1/ é velarizado em posição de coda, sendo realizado como [ł]. Esse posicionamento baseia-se em conversas e gravações com falantes nativos do kabuverdianu, nas quais a variante velarizada foi a única encontrada em posição final de sílaba (medial ou absoluta). 
são da nasalidade dessa consoante para a vogal anterior e seu posterior apagamento, o que corresponde a ['kẽ.pje] e ['kẽ.te], respectivamente.

Ademais, de acordo com Rodrigues (2007, p.179), a variedade de Santiago e Fogo admite na coda apenas /, 1, s, z, N/. Já em São Vicente e Santo Antão, todas as consoantes do quadro consonantal podem aparecer na coda. Deixando de lado o caso das ilhas de Barlavento, os segmentos trazidos pela autora são basicamente os mesmos que aparecem em (7), acrescentando apenas [z, N]. O [z] pode ser visto como um alofone de /s/ quando ele antecede uma consoante sonora, como em mésmu ['mez.mu] '1. mesmo, até, 2. (o) mesmo, 3. mesmo, efetivamente, realmente'. Já o caso do arquifonema nasal é explicado pelo fato de a autora não considerar a existência de vogais nasais no âmbito fonológico. As vogais nasalizadas consistiriam de uma sequência de vogal oral + consoante nasal. Assim, nesses casos, sempre há um elemento na coda $(/ \mathrm{N} /)$. A palavra duense 'adoecer', por exemplo, teria a seguinte representação fonológica /'dueN.se/, já kondison 'condição' seria fonologicamente /koN.di. IsoN/. Desse modo, nota-se, mais uma vez, que as diferenças na análise da autora se devem a pressupostos teóricos diversos.

\section{Síntese do capítulo}

Este capítulo tratou do kabuverdianu moderno. Inicialmente, foram apontados alguns aspectos gerais da língua, como as variedades linguísticas dialetais. $\mathrm{O}$ estatuto do kabuverdianu também foi objeto de discussão: a despeito de o crioulo ser a língua materna de grande parte da população cabo-verdiana, a língua oficial do arquipélago é o português, o que ilustra uma situação de diglossia. Em seguida, aspectos da fonologia da língua foram discutidos, apresentando os inventários vocálico e consonantal, algumas de suas particularidades (como a oposição entre as vogais médias-baixas e médias-altas funcionando como marcador da classe gramatical da palavra e a presença de consoantes nasalizadas), a estrutura silábica e os elementos que podem estar no núcleo, onset e coda. Tratar de tais aspectos permite que se conheçam os padrões e restrições do kabuverdianu, o que explica as mudanças (em diferentes níveis) que ocorreram quando palavras do português entraram na língua.

\section{Referências}

Agostinho, Ana Lívia dos Santos. Fonologia e método pedagógico do lung'Ie. 446f. Tese (Doutorado em Filologia e Língua Portuguesa) - Faculdade de Filosofia, Letras e Ciências Humanas, Universidade de São Paulo, São Paulo, 2015. 
Araujo, Gabriel Antunes de. Truncamento e reduplicação no português brasileiro. Revista de Estudos da Linguagem, Belo Horizonte, v. 10, n. 1, p. 61-90, 2002.

Brüser, Martina et al. Dicionário do crioulo de Santiago (Cabo Verde) com equivalências de tradução em alemão e português, elaborado por Martina Brüser e André dos Reis Santos (Cabo Verde), com a contribuição de Ekkehard Dengler e Andreas Blum, sob a direcção de Jürgen Lang. Tübingen: Narr, 2002.

Cabo Verde. Decreto-lei $n^{\circ}$ 67/98. 31 de dezembro de 1998. Aprova, a título experimental, o Alfabeto Unificado para a Escrita da Língua Caboverdiana. $5^{\circ}$ Suplemento. I série, $n^{\circ} 48$.

Clements, J. Clancy. The status of Portuguese/Spanish /R/ and /r/ in some Iberian-based creole languages. PAPIA, São Paulo, v. 24, n. 2, p. 343-356, 2014.

Ferguson, Charles A. Diglossia. Word, vol. 15, p. 325-340, 1959.

Klein, Thomas B. Creole phonology typology: Phoneme inventory size, vowel quality distinctions and stop consonant series. In: Bhatt, Parth \& Plag, Ingo (Ed.). The structure of creole words: Segmental, syllabic and morphological aspects. Tübingen: Niemeyer. 2006, p. 3-21.

Ladefoged, Peter \& Maddieson, Ian.The sounds of the world's languages. Oxford: Blackwell, 1996.

Lang, Jürgen et al. Gramática do Crioulo da ilha de Santiago (Cabo Verde). 2002. Disponível em: <http://iilp.wordpress.com/2012/11/14/uma-gramaticado-crioulo/>. Acesso em: 12 nov. 2013.

Lang, Jürgen. A origem das consoantes pré-nasalizadas do crioulo de Santiago (Cabo Verde). PAPIA, São Paulo, v. 24, n. 1, p. 149-170, 2014.

Lopes, Francisco João. Para uma análise sintática das construções relativas no crioulo da ilha de São Nicolau - Cabo Verde. Dissertação (Mestrado em Filologia e Língua Portuguesa) - Faculdade de Filosofia, Letras e Ciências Humanas, Universidade de São Paulo, São Paulo, 2012.

Miranda, Wânia. O sintagma nominal do caboverdiano: uma investigação semântica. Dissertação (Mestrado em Linguística) - Faculdade de Filosofia, Letras e Ciências Humanas, Universidade de São Paulo, São Paulo, 2013.

Pratas, Fernanda. O sistema pronominal do caboverdiano (variante de Santiago). Dissertação (Mestrado em Linguística) - Faculdade de Ciências Sociais e Humanas, Universidade Nova de Lisboa, Lisboa, 2002.

Quint, Nicolas. Grammaire de la langue Cap-Verdienne. Paris: L'Harmattan, 2000a.

Quint, Nicolas. Le capverdien: origines et devenir d'une langue métisse. Paris: L'Harmattan, $2000 \mathrm{~b}$.

Quint, Nicolas. Parlons Capverdien, langue et culture. Paris: L'Harmattan, 2003.

Rodrigues, Ulisdete. Fonologia do caboverdiano: das variedades insulares à unidade nacional. Tese (Doutorado em Linguística) - Instituto de Letras, Universidade de Brasília, Brasília, 2007.

Schuchardt, Hugo. O crêolo de Cabo Verde. Breves estudos sobre o crêolo das ilhas de Cabo Verde, offerecidos ao dr. Hugo Schuchardt. Boletim da Sociedade de Geographia de Lisboa $6^{\text {a }}$ série, $n^{\circ} 6$ [S. 325 - 388 des ganzen Bandes]. Lisboa, Imprensa nacional, 1886. In: Behaghel, Otto; 
Neumann, Fritz (Ed.). Literaturblatt für germanische und romanische Philologie, v. 8, 1887, p. 132-141.

Silva, Marilu Dias da. Há artigos no Crioulo de Cabo Verde, variedade de Santiago? Dissertação (Mestrado em Filologia e Língua Portuguesa) - Faculdade de Filosofia, Letras e Ciências Humanas, Universidade de São Paulo, São Paulo, 2008. 